This is a self-archived version of an original article. This version may differ from the original in pagination and typographic details.

Author(s): Reus, Tim

Title: Not a footprint to be seen : isolation in the interplay between words, music and image in two Dutch-language dubbed versions of 'Let it go'

Year: 2020

Version: Accepted version (Final draft)

Copyright: (c) Taylor \& Francis, 2019

Rights: In Copyright

Rights url: http://rightsstatements.org/page//nC/1.0/?language=en

Please cite the original version:

Reus, T. (2020). Not a footprint to be seen : isolation in the interplay between words, music and image in two Dutch-language dubbed versions of 'Let it go'. Perspectives : Studies in Translation Theory and Practice, 28(2), 271-283. https://doi.org/10.1080/0907676X.2019.1653947 


\title{
Not a footprint to be seen: Isolation in the interplay between words, music and image in two Dutch-language dubbed versions of 'Let it go'
}

\begin{abstract}
Animated musical films, such as Disney's Frozen, have long been immensely popular among the globe; however, the investigation of the songs of such films in a dubbing context constitutes a relatively new area of research. This paper compares the theme of isolation in one song from Frozen, 'Let it go', in the two Dutchlanguage dubbed versions released in, respectively, the Netherlands and Belgium. The triangle of aspects, an analytical model for animated musical films, is used to analyse the musical, visual, and verbal codes of 'Let it go' and categorise differences between the TTs and the ST. This model combines qualitative and quantitative data to compare different-language versions of songs from animated musical films. The analysis finds that the TT-NL is most similar to the ST concerning musical aspects such as rhyme scheme and rhythm, and expresses the theme of isolation most strongly through the connection between the lyrics and the music. The TT-BE is most similar concerning verbal aspects, such as semantic meaning and style, and expresses isolation most strongly through metaphor and symbolism. It is hoped that this exploration of the research field of animated musical film song dubbing stimulates further research into the genre.
\end{abstract}

Keywords: Dubbing, Dutch, Frozen, song translation, triangle of aspects

\section{Introduction}

As a surprise smash hit and one of the most successful animated musical films in history (IMDb, 2018), Disney's Frozen has been hailed as a revival for both Disney and the genre of the animated musical film as a whole (e.g. Malach, 2014; Yee, 2014). Its most popular song, 'Let it go', saw radio play for years after the film's release (Box Office Mojo, 2014; Kit, 2013). Its lasting success is not limited to the US, but has also spread abroad, as attested to by, for example, the Dutch and Belgian press at the time (Het Laatste Nieuws, 2014; Wensink, 2014). While the genre of animated musical film has arguably been popular across the world since the release of Disney's Snow-White 
and the Seven Dwarfs in 1937 (Hand et al., 1937), however, the role of the translation - and more specifically, the dubbing - of the songs from this genre has not received great academic interest within Translation Studies (Susam-Sarajeva, 2008; Chaume, 2012).

Song dubbing for animated musical films is a multimodal genre combining musical, visual, and verbal elements, and research into the topic necessarily combines song translation and musicology research (Kaindl, 2005; Low, 2005; Franzon, 2008) with dubbing and film studies research (Chaume, 2004, 2012; Pérez-González, 2014). According to Low’s (ibid.) pentathlon principle for song translation, translators should balance the five criteria of rhyme, rhythm, singability, sense, and naturalness. Chaume (ibid.) addresses the importance of lip synchrony and utterance length in dubbing film, as well as visual references such as nodding or waving. Musicology and film studies research (Clendinning \& Marvin, 2010; Monaco, 2013) stresses the importance of the emotional content of the musical and visual codes, respectively, and how the lyrics respond to those codes. These elements have been tentatively combined in an analytical model focused specifically on song dubbing: the triangle of aspects (Reus, 2017, 2018).

The aim of this study is to explore one of the primary themes of 'Let it go' - isolation - and to investigate how that theme has been developed in the original, English-language version of the song (to be called the source text, or ST), the dubbed version released in the Netherlands (the Netherlands target text, or TT-NL), and the Dutch-language dubbed version released in Belgium (the Belgian target text, or TT-BE). The focus on a single theme allows for a comprehensive analysis of the musical, visual, and verbal aspects and of the effect that the treatment of those aspects in the TTs has on the development of the theme. Section 2 concerns the theme of isolation in the film and the song; section 3 explains the triangle of aspects in greater detail; section 4 briefly discusses the results of the analysis; section 5 analyses the theme of isolation in the two TTs and offers a comparison of isolation between the TTs; and section 6 concludes the study with a brief contextualisation of 
the findings and recommendations for further research.

\section{Material}

Released in the United States on 27 November 2013 (Frozen, 2014), Frozen marked the beginning of a rise in popularity for Disney (e.g. Duralde, 2013; Malach, 2014; Muhanna, 2014). The film's popularity is not restricted to the US, as illustrated by the sheer number of languages it has been dubbed in: 43 and counting (Giese, 2018). For the Netherlands and Belgium, two different Dutchlanguage dubbed versions were produced: one released in Belgium on 4 December 2013 and the other released in the Netherlands on 11 December 2013 (Buck \& Lee, 2013). Both were received as positively as the source text (Het Laatste Nieuws, 2014; Wensink, 2014). The variety of Dutch spoken in these two countries does not differ significantly (concerning mainly pronunciation and vocabulary), and the TTs can thus be considered synchronous same-language translations. The two translations seem to have been produced largely independently of each other. For reasons of copyright, the ST and TT lyrics have not been appended; however, they are available online by using search engine keywords such as 'Let it go lyrics' for the ST, 'Laat het los lyrics Nederlands' for the TT-NL, and 'Laat het los lyrics Vlaams' for the TT-BE. In addition, the analysis of the ST and TTNL is available in the Language Bank of Finland (Kielipankki, 2019).

Telling the story of the orphaned princess sisters Elsa and Anna, Frozen has been lauded for its lack of clear male love interest and its rejection of the notion of true love (Yee, 2014), as well as the journey of Elsa, from isolation and oppression by social norms to self-acceptance and liberation (Beaudry, 2015). Elsa's journey is expressed perhaps most strongly in the song 'Let it go' (Beaudry, 2015), written by the songwriting couple Kristin Anderson-Lopez and Robert Lopez (Buck \& Lee, 2013). In the film, Elsa spends her childhood in fearful isolation after accidentally almost killing her sister during a momentary lapse of control of her mysterious ice powers (Buck \& Lee, 2013, 00:05:10). As she grows up, her powers become stronger and more uncontrollable, and during her 
coronation ceremony years later, her powers spiral out of control catastrophically. She flees the palace, and, for the first time since the incident of her youth, she is outside, and, to some extent, free (Buck \& Lee, 2013, 00:31:05). This is the moment Elsa sings 'Let it go', expressing, as she is seen constructing an ice palace on a secluded mountain top, her struggle between, on the one hand, suppressing her powers, isolating herself for the safety of others and herself, and adhering strictly to her childhood's protective mantra of keeping her powers secret; and on the other hand, releasing her powers, abandoning her old fears, and discovering what she is capable of.

The central focus of the song is the conflict between the themes of oppression and liberation (Yee, 2014). To Elsa, both can be found in isolation: in her youth, her isolation was the result of oppression and fear - her parents' as well as her own; while on the mountain top, her isolation is the result of liberation - she has chosen to isolate herself in order to discover what she can do. The song describes this shift in Elsa's perspective of isolation, from fearful to liberating. The beginning of the song sees Elsa uncertain about her decision to flee the city, but the choruses introduce optimism, excitement, and, eventually, growing confidence. The song incorporates several prominent metaphors for isolation: the storm, representing the liberating effect of isolation; the cold, representing the familiar, social isolation of Elsa's childhood; the distance, representing a new form of isolation that concentrates on physical distance to other people; and the door, representing, as it does throughout the entire film, the power Elsa herself has concerning her isolation (Beaudry, 2015; Yee, 2014). The cold and the door, whereas negative earlier in the film, are positive in 'Let it go', as illustrated by line 22, 'The cold never bothered me anyway', and line 18, 'Turn away and slam the door' (Buck \& Lee, 2013). The storm and the distance are new metaphors in this song, and although negative at first (see, for example, lines 5-7, 'The wind is howling like this swirling storm inside / Couldn't keep it in / Heaven knows I've tried'), they, too, become symbols of empowerment. In line 21, for example, Elsa sings 'Let the storm rage on', now welcoming the storm, and lines 23-24, 'It's funny how some distance / Makes everything seem small', express Elsa's relief at having left socie- 
ty behind. Within the context of Elsa's character development, then, the theme of isolation plays a central role, and the theme undergoes an important development in 'Let it go'.

\section{Methods}

The triangle of aspects, first introduced in Reus (2017), details various musical, visual, and verbal aspects that constitute constraints for the dubbing of songs for animated musical films. Each of these aspect categories (i.e. the musical, the visual, and the verbal) represents a side of the triangle. It is important to note, in this regard, that the musical side of the triangle does not concern the music itself, but only the music-related constraints on the lyrics. The same applies to the visual side. The musical side comprises four aspects, and the visual and verbal sides have three aspects each, for a total of ten aspects. The aim of the triangle is to offer not only concepts for a qualitative analysis, but also tools to gather numerical data and compare a TT to a ST on a more quantitative basis. This combination of qualitative and quantitative data can be used to analyse how a TT differs from the ST and what those differences might mean for the song's themes or characterisation, the dubbing process, or the priorities of the dubbing commission, for example.

The musical side of the triangle comprises the aspects of rhyme, rhythm, singability, and harmony. These aspects represent the musical constraints that govern the dubbing process. Rhyme concerns the rhyme scheme of the song, as well as important instances of repetition (Low, 2005, 2017). Rhythm concentrates on differences in line length (or number of syllables) and stress pattern (Low, 2005; Franzon, 2008). Singability concerns primarily vowel quality: the more open the vowel, the more singable the syllable (Low, 2017). Syllables are categorised as unstressed, stressed, and strongly stressed, based on criteria including note length and pitch. In this system, stressed syllables are simply those with prosodic or intonational stress, and any syllables that are noticeably longer or higher-pitched than that are strongly stressed. Harmony is the qualitative aspect that concerns the relation between the lyrics and the emotional effect of the music itself, as dictated by issues includ- 
ing chord progression, key, and tempo (Clendinning \& Marvin, 2010). According to Kaindl (2005), the music can illustrate, amplify, or provide disjuncture to the lyrics. For this aspect, a musicological analysis of the song is compared to the lyrics of all versions.

The aspects on the visual side are synchrony, visual deixis, and imagery. These aspects represent the constraints that the visual code introduces. Synchrony concerns the degree of agreement between lip movement and utterance, comparing the mouth shapes (which for descriptive purposes is based on vowel quality) to the syllables uttered (Chaume, 2012). Distinctions are made between front and back vowels as well as close, mid, and open vowels. Visual deixis comprises deixis referring to on-screen objects, including gestures and facial expressions (Levinson, 2004) as well as other kinetic features with cultural meaning (Chaume, 2004). The qualitative aspect of imagery represents the relation between the lyrics and the emotional effect of the visuals: e.g. use of colours, lighting, viewpoint, movement, and montage (Monaco, 2013). The relation between the lyrics and the visuals can again be illustrative, amplifying, or disjunctive (Kaindl, 2005).

On the verbal side, the aspects are those of sense, style, and mood. Based on Low $(2005,2017)$ and Chaume (2012), sense simply concerns the semantic meaning of the lyrics. The semantic meaning of the TTs is compared to the ST to determine the degree of difference per line: major (a complete change of the semantic message), minor (e.g. one of a multiple of messages is eliminated, or a metaphor is not retained, or the meaning has been altered slightly but not significantly), or none. Style concerns the register and naturalness of the lyrics. In this regard, a loose system of simple, average, or complex grammatical structure and vocabulary is used on the basis of criteria established by Halliday \& Matthiessen (2004) and Leech \& Short (2007). Such criteria include word length (longer words are more complex), word origin (in English, Latinate words are generally more complex than Germanic words), and number of subclauses in the sentence (more is more complex). According to Leech \& Short (2007), simple structures generally imply colloquial style and complex structures 
more formal language. Mood is the qualitative aspect on the verbal side, governing the relation between the lyrics and the narrative itself, including elements such as characterisation, plot, symbolism, and themes. The resulting narrative analysis of the film, and of the position of the song within the film, can again illustrate, amplify, or provide disjuncture to the lyrics (Kaindl, 2005).

The triangle of aspects analysis first identifies the values for each of the quantitative aspects in the ST and the TTs. The unit of analysis in this regard is the song line. For the more qualitative aspects (i.e. harmony, imagery, and mood), the analysis comprises a description and discussion of the relevant features in the ST; these descriptions and discussions may provide helpful insights and contextualisation for any interpretation of the findings. This study uses the triangle of aspects to discuss the role of isolation in 'Let it go' in the two TTs, and then compares the TTs to each other to explore the effects of the differences.

\section{Results}

The numerical results of the triangle of aspects analysis are summarised in table 1.

[insert table 1 here]

From left to right, the table categorises the findings according to side of the triangle, aspect, and variable, and compares the findings of the ST to those of the two TTs. These results are explained in more detail in sections 4.1 to 4.3 , addressing the differences on, respectively, the musical, visual, and verbal sides of the triangle.

\subsection{Musical analysis}

Musically, both TTs include roughly the same degree of difference from the ST. The TT-NL not 
just removes the more distant rhymes (such as lines 1 and 5, 'tonight' and 'inside', in Dutch 'vannacht' and 'weet'), but also adds rhymes, possibly as a form of compensation (such as lines 30 and 32, 'free' and 'sky', in the TT-NL 'vrij' and 'mij'). The TT-BE removes a significant number of rhymes, but also compensates by adding rhymes (most prominently the rhyme found in lines 5 and 7, again in lines 29-30, and finally in lines 40 and 42).

Rhythmically, the ST includes one instance of marked stress (line 38, where 'into' receives stress on the second syllable). The three lines with different syllable count from the ST in the TT-NL can be found in lines 2, 5, and 50, and the two instances of marked stress in lines 6 and 39. In the TTBE the two lines with different syllable count from the ST are 32 and 46, and the three instances of marked stress pattern can be found in lines 2, 22, and 48. Line 2, 'Not a footprint to be seen', is dubbed in the TT-NL as 'Van een voetstap geen blijk' ('No sign of a footprint'), in which the one missing syllable is compensated for by a melisma on 'geen' ('no'). The TT-BE maintains the number of syllables but instead pronounces 'voetafdruk' in 'En geen voetafdruk te zien' ('And no footprint to be seen') as /vu:t'afdrœk/, whereas unmarked stress would be on the first syllable (i.e. /'vu:tafdrœk/).

Concerning synchrony, the lyrics include 93 stressed syllables (i.e. syllables that receive prosodic stress as well as some melodic stress) and 50 strongly stressed syllables (i.e. syllables that receive strong melodic stress, for example by being maintained for longer than a second or by being near the top of the singer's vocal range). The TT-NL includes more close as well as more open vowels than the ST, whereas the TT-BE includes significantly more open-mid vowels, at the expense of, primarily, close-mid vowels. The TT-BE changes may seem smaller than the TT-NL changes, but the difference between both TTs is not large.

\footnotetext{
${ }^{1}$ All back-translations are mine.
} 
Concerning the aspect of harmony, 'Let it go' is a common time song in the parallel keys of $\mathrm{f}$ for the verses and A flat for the chorus. The verses have a chord structure of i-VI7-VII-iv, the prechorus, during which Elsa's theme is sung (the 'conceal, don't feel' part), are VII-VI, and the chorus (in the parallel major key) I-V-vi-IV. The song begins with high piano notes describing the tonic chord, and over the course of two verses, three choruses and a bridge, the orchestration swells to a full orchestra. The final chorus is concluded by high piano notes mirroring the introduction, describing the tonic chord, this time in the parallel major key. The vocal melody mirrors this growth in intensity: it begins relatively low and monotonous, but includes large intervals and high notes towards the end. Both TTs have reproduced the ST's primarily illustrative relation between the music and the lyrics.

\subsection{Visual analysis}

On the visual side, the TT-NL includes significantly more differences from the ST than the TT-BE. The song contains 12 lines during which the singer's mouth is either too far away to be interpreted meaningfully, or simply not on screen, and the remaining 38 lines represent 189 syllables for which lip movement can be clearly discerned. A good example of the different approaches between the two TTs is line 14, 'Well now they know'. The TT-NL renders this as 'Da's nu te laat', singing the vowels /a y $ә$ a/ where the screen shows a close-up of Elsa making mouth movements resembling the vowels $/ \varepsilon$ av er $\mathrm{a} /$. In the TT-NL, then, this line includes three major differences. In the TT-BE, on the other hand, the line is 'Hier houdt het op', /i: a $\varepsilon \mathrm{o}$ /, which has only two minor differences (i.e. the first and fourth vowels).

The ST lyrics comprise 20 instances of visual deixis, where the singer verbally refers to something seen on the screen. The TT-NL retains most of these references, but also eliminates a significant number. The reference that was replaced with a semantically unrelated reference can be found in line 49 , 'Let the storm rage on', which is sung while showing a panorama shot of Elsa's ice palace 
(thus highlighting the magnificence of what her powers can do if left to rage freely, like the storm earlier in the song). The TT-NL version is 'Vrij en onbevreesd', 'Free and unafraid', which focuses instead on Elsa spreading her arms confidently. The TT-BE retains more of the verbal references than the TT-NL, and alters more than it eliminates. The one reference replaced by a semantically unrelated reference can be found in line 48 , which replaces the focus on the 'light of day' with the fact that Elsa passes through a door in 'Maak ik mijn entree', 'I make my entrance'.

Most of the song takes place during the night, with the only source of illumination being a faint moon. Elsa is dressed initially in muted colours - the colours of her youth and the society she has fled from, as well as her surroundings, except for the light blue snow. The shapes reinforce this theme of oppression by society: the snow and Elsa herself consist predominantly of round shapes while Elsa's crown has sharp, Gothic-like forms. The ice palace, and Elsa's new dress worn halfway through the song, are significantly brighter. The shapes mirror those of the flashes of ice magic seen in the beginning of the song. At the end of the song the sun rises, casting bright orange light across Elsa's new palace. As Elsa's confidence grows over the course of the song, the colours brighten and her magical powers grow. The architecture of the ice palace resembles Elsa's childhood palace, implying that isolation is still an important theme to her, but this time the isolation is bright, rather than dark. Whereas the ST and TT-BE visual codes illustrate roughly as much as they amplify the lyrics, the TT-NL visual code amplifies significantly more. This is mostly the result of the more abstract lines, such as 47 to 49, 'Here I stand / In the light of day / Let the storm rage on', translated as 'Hier begint / Nu mijn leven weer / Vrij en onbevreesd' ('Here starts / Now my life again / Free and unafraid'), lacking a reference to the daylight and the storm.

\subsection{Verbal analysis}

Whereas the TT-NL differs roughly as strongly from the ST with regard to verbal aspects (e.g. sense and style) as visual aspects (e.g. synchrony and visual deixis, described above), the TT-BE 
includes fewer differences from the ST on the verbal side of the triangle than on any other side. An example that illustrates the difference between the TT-NL and the TT-BE can be found in lines 35 to 37, 'Here I stand / And here I'll stay / Let the storm rage on'. The TT-NL dubs these lines as 'Hier begint / Mijn nieuw bestaan / Onbevreesd en vrij' ('Here starts / My new life / Unafraid and free'), expressing a quite different sense and excluding the metaphor of the storm, whereas the TTBE dubs these lines as 'I $k$ sta hier / En ik blijf hier / En de storm raast door' ('I stand here / And I'll stay here / And the storm rages on'), conveying a message much more similar to the ST and retaining the metaphor of the storm. Lines 47 to 49 , quoted in the previous paragraph, include similar differences.

The style of the ST is generally simple, containing mostly simple vocabulary and grammatical structures and no complex vocabulary or grammatical structures. The TT-NL is more complex than the ST, while the TT-BE has a stylistic complexity roughly comparable to the ST. A telling example is line 19, 'I don't care', which is quite simple by most linguistic standards. The TT-BE version translates this line as 'Ik geef niet om' ('I don't care about'), linking it a little more formally to line 20. The grammatical structure was assessed to be of average complexity, rather than simple, but the vocabulary is still quite simple. The TT-NL version, however, translates this line as 'Wat men daar' ('What the ones there'), inverting the grammatical structure of lines 19 and 20 (i.e. 'I don't care / What they're going to say'), which is a more complex, formal, and, perhaps, literary grammatical structure in Dutch than a non-inverted solution would be, and the word 'men' (the impersonal pronoun 'one') is quite formal and arguably even old-fashioned in Dutch today.

For the aspect of mood, the song primarily constitutes an important moment of character development for Elsa. Whereas she has always considered isolation a necessary, albeit oppressive, tool to suppress her powers, in this song she discovers how isolation can be liberating as well. This dichotomy between oppression and liberation, expressed by means of the metaphors of the storm, the 
cold, the distance, and the door, becomes dominant in key lines such as 22 , 'The cold never bothered me anyway', and 23 to 24, 'It's funny how some distance / Makes everything seem small', referring to Elsa embracing her isolation; and identical lines 21, 37, and 49, 'Let the storm rage on', showing Elsa developing her understanding of her powers. The titular lines, 'Let it go', combine the metaphor of the storm and Elsa's powers - she is letting go of her powers so that they can be free, like a storm - with her development as a liberated character - the more she experiments with her powers, the more confident she grows. The symbol of the door, up until this point in the film used as shorthand for shutting people out, is developed here into a symbol of control and safety for Elsa: in line 18, 'Turn away and slam the door', for example, she expresses the voluntary nature of her isolation. By the end of the song, isolation is no longer something imposed on Elsa, but rather something she chooses and is in control of. The TT-NL mentions the storm only 2 times, rather than the 4 of the ST and the TT-BE, and the freedom of isolation is expressed 7 times in the ST, 6 in the Belgian, and only 4 in the TT-NL.

\section{Discussion}

\subsection{Isolation in the TT-NL}

The development of isolation has, in general, been reduced in the TT-NL. On the musical side, however, the TT-NL expresses this development to a degree similar to the ST, although in a fashion quite different. The ST uses the lyrics' singability to develop isolation in unison with the harmony, beginning with many close and close-mid vowels and ending with many open and open-mid vowels to express Elsa's development from isolation to liberation, while the rhyme scheme offers a sense of unity and continuity to the development. In lines 7 and 8, 'Heaven knows I tried / Don't let them in', for example, which constitute, respectively, the end of the first verse and the start of the prechorus section, the ST uses the A-rhyme in line 7, referencing the first line, and the D-rhyme in line 8, reinforcing its connection to line 6 (thus creating a pattern of ABCB ADAD). The TT-NL uses 
the D-rhyme in line 7 (referencing line 5 rather than line 1) and introduces a new rhyme in line 8 (ABCB ZDZY). Whereas the TT-NL uses the rhyme scheme to distinguish between the stages of the development of isolation, then, it uses singability in a more unifying fashion than the ST, effectively inverting the functions of those aspects concerning the theme of isolation and maintaining its development.

The reduced development of isolation in the TT-NL is instead the result of the visual and verbal sides. Synchronic differences between utterances and mouth movements may break suspension of linguistic disbelief: characters' mouth movements look unnatural or impossible. Most synchronic differences in the TT-NL can be found in lines 1 to 7, which establishes Elsa's sadness, and lines 23 to 27, which, conversely, develop Elsa's confidence and excitement. As such, the aspect of synchrony undermines the audience's interpretation or understanding of both Elsa's initial fears and her growing confidence after the first chorus. In this sense, synchrony weakens the emotional impact of Elsa's initial confusion and reduces the development of her confidence. Visual deixis seems to support her fears more strongly, since most of the removed instances of visual deixis can be found towards the end, where Elsa is more confident. A telling example can be found in line 46, 'That perfect girl is gone', sung while looking at her crooked reflection in the ice of her palace. The TT-NL translates this line as 'Op deze hoge top' ('On this high peak'), ignoring Elsa's visual selfreflection. This removes the notion of conquering one's own insecurities, which is a primary element of the theme of isolation.

Verbally, too, there are many major changes in the TT-NL especially towards the end of the song. The bridge, discussing a colonnade of stone, rather than a palace of ice as in the ST, and the final chorus, removing most references to the voluntary nature of her isolation while expressing Elsa's newfound confidence rather more directly, leave little room for the connection of isolation in the song to the rest of the film. While TT-NL line 46, quoted in the previous paragraph, refers to the 
isolation around her (possibly as a form of compensation), lines 47 to 49 discuss not the light of day and the raging storm as a representation of Elsa's freed powers, but simply a restart of her life (i.e. 'Hier begint / Nu mijn leven weer / Vrij en onbevreesd', 'Here starts / Now my life again / Free and unafraid'). These lines are typical of the TT-NL in that they include fewer references to the visual code or the film's metaphors than the ST, instead opting for a more direct, unambiguous, and, perhaps, less emotionally compelling approach.

\subsection{Isolation in the TT-BE}

The development of isolation in the TT-BE has also been reduced slightly on a general level, but in ways different from the TT-NL. On the musical side, the TT-BE differs most significantly from the ST concerning the aspect of singability, describing a lack of development from close to open vowels similar to the TT-NL. This uniformity of vowel quality throughout the song is not as strong as in the TT-NL, but it is also not contrasted by a development of isolation in the rhyme scheme, which instead performs a similarly unifying function in the TT-BE as in the ST. Rhythmically, while close to the ST, the TT-BE includes some differences in line length and stress pattern towards the end, and especially the two added syllables in line 46, 'That perfect girl is gone', translated as 'Die brave meid is er vandoor' ('That good girl is gone'), sound awkward. This line might be seen to undermine the growth of Elsa's confidence, but in truth this is only one line and has a minor impact.

On the visual side, it is the aspect of synchrony that includes most differences from the ST. Unlike the TT-NL, however, the differences are distributed fairly evenly across all lines, rather than concentrating only on the verse sections, and they are less pronounced than in the TT-NL verses, thus having little effect on the audience's interpretation of the development of isolation. Visual deixis in the TT-BE includes most differences in the first half of the song. Most of these changes are not eliminations of the reference to the visual code, however, but effective alterations or slightly weakened formulations of the same idea. For example, lines 10 and 11, 'Be the good girl / You always 
have to be', are translated as 'Je moet altijd / Het brave meisje zijn' ('You always have to be / The good girl'), sung while wagging her finger in an imitation of a strict parent. The TT-BE does not use the imperative form and the switch of the semantic loads between the lines weakens the impact of seeing the finger-wagging during the first line, but apart from that, a similar reference is maintained.

The TT-BE is least different from the ST on the verbal side. There are some minor changes in the denotations of lines, especially in the beginning, but semantically, the TT-BE is exceedingly close to the ST. Stylistically, too, the TT-BE is close to the ST, employing a similarly colloquial, if occasionally surprisingly formal, register. On this side, then, the development of the theme of isolation is strikingly similar to the ST, employing the same metaphors and symbols in roughly the same fashion. One difference, however, is that the connection between the symbols of the storm and the cold are occasionally less directly related to Elsa, making her seem less in control of the development of isolation. For example, the repeated line 'Let the storm rage on' implies that Elsa has the option of stopping the storm if she wanted to, while the TT-BE, 'En de storm raast door' ('And the storm rages on'), does not imply such control. This does not necessarily affect the development of isolation, however: merely the level of conscious control Elsa has of that development.

\subsection{Comparing the TT-NL and TT-BE}

While in general, the TT-BE includes fewer differences to the ST than the TT-NL, the TT-NL is closer on the musical side. The TT-NL inverts the functions of the aspects of singability, rhyme and rhythm in the development of isolation, and thus supports the theme as strongly as the ST. In the TT-BE, singability has a unifying function similar to the TT-NL, but the rhyme scheme and rhythm have a unifying function similar to the ST. As a result, the development of isolation is weakened in the TT-BE on the musical side, whereas the TT-NL maintains the contrast between Elsa's growing confidence and the fact that she remains isolated from start to finish. 
On the visual side, however, this contrast between fear and confidence is weakened in the TT-NL by its selective synchronic differences. Whereas the TT-BE includes fairly even synchronic dissimilarity to the ST, the TT-NL's differences concentrate on the verse sections, thus distracting the audience when the lyrics imply a more confident or optimistic mindset. Concerning visual deixis, the difference between the TTs is even starker: the TT-NL stresses Elsa's fear in the second half of the song, whereas the TT-BE stresses Elsa's liberation at the end but weakens the connection to the visual code at the beginning, widening the gap between initial confusion and later confidence. On the visual side, then, the TT-NL includes many differences that reduce the development of isolation as expressed on the musical side, while the TT-BE increases the development of isolation that had been reduced on the musical side.

The most significant differences between the two TTs, however, can be found on the verbal side. The TT-BE is exceedingly close to the ST concerning the aspects of sense, style, and mood, while the TT-NL includes some meaningful differences from the ST, ranging from major semantic changes in the second half of the song, eliminating metaphors from the lyrics, to a more complex, formal style, complicating Elsa's character development during the song. Whereas the TT-BE follows the development of isolation as expressed in the ST quite closely, the TT-NL undermines that development, replacing metaphors and characterisation by explicit statements to tell the audience how Elsa feels. The TT-NL, then, expands Elsa's growth and the development of isolation primarily through musical means, whereas the TT-BE employs primarily verbal means, and secondarily visual, to develop isolation. Both TTs, however, seem to share a general, if slight, reduction of the development of isolation.

\section{Conclusion}

The TTs of 'Let it go' investigated here adopt different strategies to convey the theme of isolation. 
In the TT-NL, isolation is expressed primarily through the music, while differences of lip synchrony and limited inclusion of metaphors undermine the audience's interpretation of Elsa's growing confidence over the course of the song. The TT-BE, instead, limits Elsa's growth on the musical side, expressing the theme primarily through verbal means and visual deixis. While there may seem to be a correlation between similarity to the ST on a certain side of the triangle of aspects and the development of isolation on that side, that is not always the case. Differences have also been introduced to develop the theme, such as in the aspects of rhyme and rhythm in the TT-NL, or visual deixis in the TT-BE. While the focus of these two TTs might be different, then, the overall effect of the dubbing strategy on the theme of isolation is comparable, in that the development of isolation seems to have been slightly reduced in the TTs compared to the ST.

Reus (2018) argues that the focus of the TT-NL songs from Frozen was primarily on the musical side, concentrating not as strongly on maintaining a close relation between the visual code and the lyrics, or on the semantic meaning of the lyrics. By analysing a second, synchronic Dutch-language version of the songs, this study provides a useful context for those findings. Whereas the TT-NL adopts a relatively musicocentric approach, then, the TT-BE is more logocentric, concentrating on semantic meaning as well as themes and symbolism more than on adherence to the musical or visual constraints imposed by the ST. The triangle of aspects for song dubbing, first introduced in Reus (2017), is expanded upon and implemented in a generally qualitative comparison of theme. It has been found that the numerical data generated by the triangle of aspects is a valuable tool to support the qualitative analysis - especially concerning a translational genre as complex as animated musical film.

This study concerns only two dubbed versions of a single animated musical film song, so its scope is quite limited. Further research may involve other dubbed versions - ideally of language pairs that are perhaps less closely related than English and Dutch - to facilitate a more comprehensive com- 
parison between dubbing strategies in other language areas and to assess their effects on themes such as isolation. Another interesting avenue of research involves different topics: narrative ones, such as characterisation or symbolism; visual ones, such as use of colour or the implications of the visual design; or musical ones, such as repeated sounds or the implications of chord progressions and melodies. These findings may also be contextualised by research into the dubbing process of 'Let it go' in the Netherlands and Belgium, or into the reception of the TTs in their respective target cultures. Ultimately, song dubbing of animated musical films is still a quite new research area, and it is hoped that this study generates more interest among scholars.

\section{References}

Beaudry, K. (2015). Disney melodies: The magic of Disney music. New York: Theme Park Press.

Chaume, F. (2004). Synchronisation in dubbing: A translational approach. In P. Orero (Ed.), Topics in audiovisual translation (35-52). Amsterdam and Philadelphia: John Benjamins.

Chaume, F. (2012). Audiovisual translation: Dubbing. Manchester: St Jerome Publishing.

Clendinning, J. P., \& Marvin, E. W. (2010). The musician's guide to theory and analysis (2nd ed). New York: W. W. Norton \& Company.

Buck, C., \& Lee, J. (Directors), \& Del Vecho, P. (Producer). (10 November 2013). Frozen [Motion picture]. United States: Disney.

Duralde, Alonso. (3 November 2013). 'Frozen' review: Disney's best animated musical since 'Beauty and the beast'. The wrap. Retrieved from https:/www.thewrap.com/frozen-reviewproactive-princesses-catchy-tunes-make-winning-combo/

Franzon, J. (2008). Choices in song translation: Singability in print, subtitles and sung performance. Translation and music, 14(2), 373-400.

Frozen. (8 December 2014). Retrieved from http://boxofficemojo.com/movies/?id=frozen2013.htm

Giese, F. (1 November 2018). Frozen dub collection. Retrieved from http://frozendubcollection.weebly.com/list-of-existing-dubs.html

Halliday, M. A. K., \& Matthiessen, C. (2004). An introduction to functional grammar. London: Arnold.

Hand, D., Cottrell, W., Jackson, W., Morey, L., Pearce, P., \& Sharpsteen, B. (Directors). (21 December 1937). Snow-white and the seven dwarfs [Motion picture]. United States: Disney.

Het Laatste Nieuws (27 December 2014). Vlaamse kindjes krijgen niet genoeg van 'Frozen'. Het 
Laatste Nieuws. Retrieved from https://www.hln.be/showbizz/film/vlaamse-kindjes-krijgen-nietgenoeg-van-frozen ad69d469/?referer=https\%3A\%2F\%2Fwww.google.fi\%2F

IMDb. (2018). Frozen. Retrieved from http://www.imdb.com/title/tt2294629/

Kaindl, K. (2005). The plurisemiotics of pop song translation: Words, music, voice and image. In D. L. Gorlée (Ed.), Songs and significance: Virtues and vices of vocal translation (235-262). Amsterdam and New York: Rodopy.

Kielipankki. (2019). Triangle of aspects analysis of Frozen [Data set]. Retrieved from http://urn.fi/urn:nbn:fi:lb-2019022701

Kit, Zorianna. (27 November 2013). Awards spotlight: Robert Lopez \& Kristen Anderson-Lopez make beautiful music together for Disney's Frozen. Studio system news. Retrieved from https://web.archive.org/web/20140129120217/http://www.studiosystemnews.com/awardsspotlight-robert-lopez-kristen-anderson-lopez-make-beautiful-music-together-for-disneysfrozen/

Leech, G., \& Short, M. (2007). Style in fiction: A linguistic introduction to English fictional prose. (2nd ed.) Harlow: Pearson Education.

Levinson, S. C. (2004). Deixis. In L. Horn \& G. Ward (Eds.), The handbook of pragmatics (97121). Oxford: Blackwell Publishing.

Low, P. (2005). The pentathlon approach to translating songs. In D. L. Gorlée (Ed.), Songs and significance: Virtues and vices of vocal translation (185-212). Amsterdam and New York: Rodopy.

Low, P. (2017). Translating songs: Lyrics and texts. Abingdon and New York: Routledge.

Malach, M. (18 April 2014). Disney renaissance: Why 'Frozen' is reviving the company's golden era of animated films. Popcrush. Retrieved from http://popcrush.com/disney-renaissance-frozenanimated-films/

Monaco, J. (2013). How to read a film: Movies, media, and beyond (4th ed.). Sag Harbor: Harbor Electronic Publishing.

Muhanna, E. (30 May 2014). Translating Frozen into Arabic. The New Yorker. Retrieved from http://www.newyorker.com/books/page-turner/translating-frozen-into-arabic

Pérez-González, Luis. (2014). Audiovisual translation: Theories, methods and issues. London and New York: Routledge.

Reus, T. (2017). The many voices of Elsa and Anna: Introducing the triangle of aspects for animated musical film dubbing. VAKKI publications, 8(1), 181-192.

Reus, T. (2018). Exploring skopos in the Dutch dubbed versions of the songs of Disney's Frozen. New voices in translation studies, 19(1), 1-24. 
Susam-Sarajeva, Ş. (2008). Translation and music: Changing perspectives, frameworks and significance. Translation and music, 14(2), 187-200.

Wensink, H. (31 December 2014). Frozen: De commerciële (kunstzinnige) truc van het jaar. NRC Q. Retrieved from http://www.nrcq.nl/2014/12/31/frozen-de-commerciele-kunstzinnige-trucvan-het-jaar

Yee, K. (2014). Let it go: A quick academic analysis of Disney's Frozen. Central Florida: Ultimate Orlando Press. 
Table 1: Differences between the ST and the two TTs

\begin{tabular}{|c|c|c|c|c|c|}
\hline \multirow{11}{*}{ Musical } & \multirow{4}{*}{$\begin{array}{l}\text { Rhyme } \\
\text { (per line) }\end{array}$} & & $\mathrm{ST}$ & TT-NL & TT-BE \\
\hline & & End-rhymes & 20 & 24 & 26 \\
\hline & & Av. repeated & 2.5 & 2.1 & 1.9 \\
\hline & & Repetition & 12 & 9 & 16 \\
\hline & \multirow{2}{*}{$\begin{array}{l}\text { Rhythm } \\
\text { (per line) }\end{array}$} & Marked stress & 1 & 2 & 3 \\
\hline & & $\begin{array}{l}\text { Altered sylla- } \\
\text { ble count }\end{array}$ & - & 3 & 2 \\
\hline & \multirow{4}{*}{$\begin{array}{l}\text { Singability } \\
\text { (per syllable) }\end{array}$} & Close & 18 & 28 & 19 \\
\hline & & Close-mid & 49 & 33 & 34 \\
\hline & & Open-mid & 51 & 52 & 64 \\
\hline & & Open & 25 & 30 & 26 \\
\hline & Harmony & $\begin{array}{l}\text { Illus./Ampl./ } \\
\text { Disjuct. }\end{array}$ & $40 / 4 / 6$ & $38 / 6 / 6$ & $38 / 6 / 6$ \\
\hline \multirow[t]{8}{*}{ Visual } & \multirow{3}{*}{$\begin{array}{l}\text { Synchrony } \\
\text { (differences } \\
\text { per syllable) }\end{array}$} & None & - & 73 & 90 \\
\hline & & Minor & - & 46 & 53 \\
\hline & & Major & - & 70 & 46 \\
\hline & \multirow{4}{*}{$\begin{array}{l}\text { Visual deixis } \\
\text { (differences } \\
\text { per instance) }\end{array}$} & Retained & - & 11 & 12 \\
\hline & & Eliminated & - & 5 & 2 \\
\hline & & Altered & - & 3 & 5 \\
\hline & & Replaced & - & 1 & 1 \\
\hline & Imagery & $\begin{array}{l}\text { Illus./Ampl./ } \\
\text { Disjuct. }\end{array}$ & $26 / 23 / 1$ & $18 / 30 / 2$ & $25 / 24 / 1$ \\
\hline \multirow[t]{8}{*}{ Verbal } & \multirow{3}{*}{$\begin{array}{l}\text { Sense } \\
\text { (differences } \\
\text { per line) }\end{array}$} & None & - & 22 & 30 \\
\hline & & Minor & - & 11 & 16 \\
\hline & & Major & - & 17 & 4 \\
\hline & \multirow[t]{3}{*}{$\begin{array}{l}\text { Style } \\
\text { (structure } \\
\text { per line) }\end{array}$} & Simple & $\begin{array}{cc}\text { voc. } & \text { gram. } \\
39 & 31\end{array}$ & $\begin{array}{cc}\text { voc. } & \text { gram. } \\
32 & 24\end{array}$ & $\begin{array}{cc}\text { voc. } & \text { gram. } \\
42 & 30\end{array}$ \\
\hline & & Average & 11 & 15 & 20 \\
\hline & & Complex & 0 & 3 & 1 \\
\hline & \multirow[t]{2}{*}{ Mood } & Storm & 4 & 2 & 4 \\
\hline & & Freedom & 7 & 4 & 6 \\
\hline
\end{tabular}

